УДК 94(430).085

О. И. Рудая

\title{
НАЦИСТСКАЯ АГИТАЦИЯ И ПРОПАГАНДА В ВЕЙМАРСКОЙ РЕСПУБЛИКЕ
}

В статье анализируются основные методы и принципы организации нацистской агитации и пропаганды в период Веймарской республики. Актуальность данной проблематики обусловлена современными общественно-политическими процессами, связанными с идеологической обработкой электората в ходе избирательной кампании для получения его поддержки на выборах.

В годы, предшествовавшие приходу к власти, гитлеровская партия активно занималась вопросами национальной агитации и пропаганды. В своей устной, печатной и практической деятельности нацисты стремились воздействовать на сознание и настроения самых широких слоев немецкого населения и с этой целью применяли специфический и разнообразный набор средств. В борьбе за влияние в массах они использовали социальную и национальную демагогию, провокации и новейшую технику своего времени.

Автор отмечает, что нацистская пропаганда была достаточно изобретательной и конъюнктурной. Нацисты искусно использовали сюжеты германской истории, что находило глубокий отклик в сердцах немцев, жаждавших общности со своим национальным наследием и историческим прошлым. Они постоянно апеллировали к вере единственной субстанции, которая придает смысл человеческой жизни и поддерживает человека в сложных условиях. Пропагандистские методы включали злобную сатиру, концентрацию на отдельном вопросе, выбранном в качестве первостепенного в той или иной социально-политической ситуации, аргументированные обвинения в адрес некомпетентного правительства, поиск и осуждение «врагов» нации. Нацистские идеологи и ораторы, прекрасно владевшие своим голосом, ловко использовали многократные повторы фрраз, настойчивые воззвания к идеализму и героизму. Пропаганда рассматривалась как искусство прагматики, как главное средство к достижению политической цели. Однако при этом никогда не переоценивалась её практическая роль и последующее влияние на массы.

Автор показывает, что при помощи активного использования средств массовой информации нацистам удалось создать широкую социальную базу своего движения.

Ключевые слова: Веймарская республика, А. Гитлер, Й. Геббельс, НСДАП, агитация, пропаганда.

\section{O. I. Rudaya}

\section{NAZI AGITATION AND PROPAGANDA IN THE WEIMAR REPUBLIC}

The article analyzes the main methods and principles of the organization of Nazi agitation and propaganda during the Weimar Republic. The relevance of this problem is preconditioned by modern socio-political processes associated with the ideological brainwashing of the electorate during the election campaign to obtain its support in the elections.

In the years preceding the coming to power, the Hitler party was actively engaged in issues of national agitation and propaganda. In their oral, printed and practical activities the Nazis sought to influence the consciousness and mood of the broadest sections of the German population and used a specific and diverse set of tools for that purpose. In the struggle for influence on the masses they used social and national demagogy, provocations and the latest technology of their time.

The author notes that Nazi propaganda was quite inventive and opportunistic. The Nazis skillfully used the plots of German history, which found a deep response in the hearts of Germans, who hungered for commonness with their national heritage and historical past. They constantly appealed to faith - the only substance that gives meaning to human life and supports a person in difficult circumstances. Propagandistic methods included vicious satire, concentration on a particular issue chosen as the paramount one in a given socio-political situation, reasoned accusations against an incompetent government, the search for and condemnation of the "enemies" of the nation. Nazi ideologists and orators, who were perfectly fluent in their voices, cleverly used multiple repetitions of phrases, persistent appeals to idealism and heroism. Propaganda was considered as the art of pragmatics, as the main means to achieve a political goal. However its practical role and subsequent influence on the masses were never overestimated.

The author shows that with the active use of mass media the Nazis managed to create a broad social base of their movement.

Key words: the Weimar Republic, A. Hitler, J. Goebbels, NSDAP, agitation, propaganda. 
Средства массовой информации как механизм воздействия на сознание широких масс населения с помощью разнообразных технических возможностей стали играть важную роль в жизни людей с момента своего появления. Их стремительное развитие в XIX и начале XX вB. создало благоприятные условия для зарождения и расцвета тоталитарных режимов и идеологий. Политические партии тоталитарного типа впервые начали активно использовать средства коммуникации и информации в своей деятельности, ориентированной на завоевание и укрепление власти. Известно, что именно широкомасштабное применение новой техники позволило национал-социалистам во главе с Адольфом Гитлером существенным образом повлиять на общественное мнение Германии и, заручившись его поддержкой, создать массовую базу своего движения, а впоследствии прийти к власти. По мнению канадского исследователя Г. М. Маклюэна, то обстоятельство, что «Гитлер вообще обрёл политическое существование, напрямую (было - О. Р.) обязано радио и системам публичных выступлений» [8, с. 152].

После поражения Германской империи в Первой мировой войне и подписания унизительного и тяжёлого Версальского договора в стране сложилась благоприятная социальноэкономическая и политическая ситуация для возникновения и роста радикальных настроений и экстремистских организаций. Созданная в результате Ноябрьской революции 1918 г. Веймарская республика с новой формой правления не только не способствовала их искоренению, но напротив, создавала дополнительный импульс для развития. Многие немцы не признали демилитаризацию и территориальные потери, навязанные им по условиям Версальского мира. В политической, и особенно в националистической среде широкую популярность приобрели идеи о «реванше», «версальском позоре» и «ударе ножом в спину». Среди множества реакционных групп и объединений, активно аккумулировавших эти тезисы, была и немецкая рабочая партия, переименованная в 1920 г. в национал-социалистическую рабочую партию (НСДАП). Её преимущества перед другими организациями состояли в том, что она смогла найти особые методы и систему распространения своего влияния на достаточно широкие слои германского населения.

В феврале 1920 г. нацисты разработали партийную программу «25 пунктов», которая с апреля того же года стала официальным документом НСДАП. Представлявшая эклектическую смесь из демагогии, реваншизма, на- ционализма и ярого антисемитизма, она изначально была ориентирована на самых разных представителей общества. Исходной точкой всех внутри и внешнеполитических воззрений составителей «25 пунктов» являлась идея национального возрождения. Именно поэтому главным лозунгом нацистов стал призыв: «Проснись, Германия!».

В отличие от других партий Веймарской республики НСДАП также выступила в качестве инициатора кампании протеста против репарационных платежей и тем самым заявила о себе как о претенденте на роль единственного «выразителя интересов нации». Как пророчески утверждал Гитлер, «наше движение первым взяло на себя задачу познакомить самые широкие слои народа с подлинным содержанием Версальского мирного договора. В этом был залог успеха нашего движения в будущем» [6, с. 390].

Практически сразу национал-социалисты развернули активную агитацию и пропаганду своих взглядов. «На 24 февраля 1920 г. мы назначили первое большое народное собрание, имевшее задачей вынести в массу идеи нашего тогда ещё неизвестного движения», - писал фюрер в своей книге «Mein Kampf» [6, с. 305].

С этого времени «25 пунктов» стали проповедоваться еженедельно на массовых собраниях её приверженцев, происходивших в мюнхенских пивных. Так, за период с 24 февраля 1920 г. по 21 февраля 1921 г. только в столице Баварии нацисты организовали 46 публичных собраний, в том числе 10 массовых, на которых присутствовало 62371 человек. Они посылали своих представителей на митинги других политических партий, где им также удавалось отстаивать собственные идеи. Тематика речей нацистских ораторов полностью соответствовала тактической линии партии и сводилась к следующему: «Международный биржевой капитал и маленький рантье», «Еврей как рабочий руководитель», «Почему мы являемся антисемитами», «Политика партии и еврейский вопрос», «Еврейское и германское народное просвещение» [3, с. 57].

В 1920-1921 гг. у национал-социалистов появился партийный аппарат и печать - еженедельная газета «Фёлькишер Беобахтер» (Völkischer Beobachter), ставшая с фревраля 1923 г. ежедневной, а также помещение для резиденции. Вскоре фрашистские организации существовали уже не только в Баварии, но и в других областях Германии. В марте 1922 г. был создан «Молодёжный союз» НСДАП, который тоже начал издавать собственную газету. К этому времени значительно расширились и 
масштабы устной пропаганды. Нацисты стали выходить за пределы пивных залов, снимать обширные помещения и даже выступать на площадях городов. В некоторых из них проводились так называемые «германские дни» массовые митинги с участием тысяч людей.

В июне 1921 г. главой партии официально стал Гитлер, получивший титул вождя и руководителя всей её организационной деятельности и прессы. Как справедливо полагает британский историк Я. Кершоу, решающим фрактором в установлении его личного превосходства была сила и уверенность в собственной правоте. Простота дуалистического видения мира как манихейской борьбы добра и зла, в которой всё доводилось до абсолюта, означавшего либо всё, либо ничего, вкупе с фанатичной жестокостью и несгибаемой твердостью сделали Гитлера незаменимым ведущим пропагандистом [7, с. 31].

В 1922-1923 гг., когда правительство Веймарской республики безуспешно пыталось справиться со стремительно росшей инфляцией и безработицей, нацистская обработка населения в духе крайнего национализма и реваншизма усилилась. «Теоретической основой» пропагандистской деятельности НСДАП стали книга Г. Федера «Германское господство на национальной и социальной основе» и брошюра Д. Эккарта «Большевизм от Моисея до Ленина. Мои беседы с Адольфом Гитлером». Обе работы, написанные влиятельными членами партии, представляли собой свод антисемитских вымыслов и рассуждений о «процентном рабстве», «заговоре мирового большевизма» и «еврейства» и логически завершались призывами к «единению нации», «национальной дисциплине» и «оздоровлению германского духа» [3, с. 61].

По представлениям национал-социалистов, проникновение подобных настроений в сознание немецкого народа способно было заложить основы его расового возрождения и создать предпосылки для дальнейшего культурного развития государства [6, с. 357]. В то же время нацистское мировоззрение, как подчеркивал Гитлер, признавало «не только великое значение расы, но и ... личности, а потому на них именно» оно и строило "всё свое здание» [6, с. 375]. Эти два фактора легли в основу агитации и пропаганды нацистской партии в период Веймарской республики.

Примечательно, что уже тогда Гитлер решительно заявлял о принципиальном намерении своего движения присвоить «себе право навязывать свои принципы всей германской нации, не останавливаясь перед границами тех или других отдельных государств» [6, с. 486]. В этом заявлении четко прослеживались тоталитарные тенденции и реваншистские устремления НСДАП и её лидера.

С самого начала своей деятельности нацисты широко использовали методы провокаций. Так, поводом для нападения на рабочих они избирали клевету о том, что якобы «марксисты хотели взорвать зал, где проводился фашистский митинг», или что-либо подобное [4, с. 30]. Для охраны своих демонстраций от «враждебных элементов» и поддержания на них порядка национал-социалисты сформировали вооруженные отряды - так называемую «службу порядка», которая в ноябре 1921 г. получила название штурмовых отрядов - СА (Sturmabteilungen - SA)

Однако до 1928 г. НСДАП не располагала серьёзной пропагандистской организацией. Её агитационная работа носила преимущественно хаотичный характер и приобрела стройную систему только после создания Имперского управления пропаганды (РПЛ) и назначения её руководителем в 1929 г. Йозефра Геббельса.

Незадолго до своего избрания на эту должность гауляйтер Геббельс произнес речь под названием «Знания и пропаганда», в которой четко заявил о том, что цель пропаганды - политический успех, а не интеллектуальные глубины. Её главную роль он видел в умении выразить словесно то, что аудитория чувствовала в своих сердцах. По мнению Геббельса, пропагандист обязан был донести национал-социалистическую идею до слушателей. Более того, в зависимости от ситуации он должен был быть писателем, организатором и оратором. Все эти качества и умения требовались для того, чтобы свободно обращаться как к «широким массам образованных людей», так и к «маленькому человеку» [5, с. 73-74]. Следует отметить, что сам Геббельс не просто обладал обозначенными характеристиками, а мастерски владел ими, став вторым оратором в иерархии НСДАП.

Для обеспечения победы идеи необходима была партийная организация. Указывая на принципиальную важность данного обстоятельства, Гитлер писал: «из всей сокровищницы идей общенароднического миросозерцания» партия «выбирает наиболее существенные, учитывая все особенности эпохи, все практические потребности дня, все слабые и сильные стороны того человеческого материала, с которым приходится иметь дело, вырабатывает определенный символ веры и на основе этой программы» строит «строго 
централизованную организацию, которая одна только и может принести победу нашему миросозерцанию» [6, с. 322].

Массовая демагогия рассматривалась лишь в качестве первого шага на пути создания социальной базы движения. Решающая роль отводилась организации, которая должна была поддерживать и распространять пропаганду. По мнению нацистских идеологов, властные структуры, в основе которых находилась лишь агитационная деятельность, были неустойчивы и недолговечны. Руководствуясь этим фрактором, нацисты и создали Имперское управление пропаганды.

Возглавлявший данное ведомство Геббельс, аналогично Гитлеру, рассматривал пропаганду как средство к достижению политической цели, как форму борьбы за власть. Ключевыми моментами его пропагандистской концепции в период существования Веймарской республики являлись идеализм, прагматизм и цинизм. «Никто не желает погибать во имя восьмичасового рабочего дня. Но кто-то может умереть за то, чтобы Германия принадлежала своему народу», - утверждал гауляйтер [Цит. по: 4, с. 74].

Глава Имперского управления пропаганды определял все направления агитационной деятельности нацистского движения, включая его отделы и фрилиалы. Руководство пропагандой на уровне административной единицы (гау) являлось представительным органом РПЛ и отвечало за проведение национальной политики партии в четырех областях: активной пропаганде, кино, радио и культуре. Окружное подразделение ведомства выполняло данные функции на более низком уровне и подчинялось начальнику местного отделения.

В соответствии с предложением Геббельса, Отдел пропаганды имперского руководства партии разработал так называемый концентрический метод, направленный на проведение «ударных пропагандистских акций». Они должны были наполнять пропагандой все районы страны не только во время предвыборной кампании, но и в течение всего календарного года. Для этой цели в каждом округе через 7-10 дней предполагалось проводить от 70 до 200 митингов [1, с. 103].

Важным элементом гитлеровской пропаганды являлись проходившие с 1923 г. съезды НСДАП. Начиная с 1927 г. местом их проведения стал Нюрнберг, чья готическая архитектура, по представлениям фюрера, наиболее полно воплощала немецкую культуру. Партийные конгрессы, представлявшие собой массовые митинги, каждый участник которого чувствовал себя увереннее и сильнее в единстве общей массы, созывались с целью демонстрации величия германской нации. Главным местом действий нацистов были Арена Луитпольда площадь для демонстраций, вмещавшая до 150000 участников, а также Зал Луитпольда вместимостью до 16000 человек, где проходили собрания. Нюрнбергским съездам отводилась особая роль, они считались наиболее действенной формой пропаганды, поэтому по окончании каждого из них создавались агитационные документальные фильмы.

Финансовая помощь со стороны крупных магнатов, открыто сделавших ставку на Гитлера, позволила нацистам относительно быстро расширить технические возможности своей агитации. Если в 1930 г. у НСДАП было 7 ежедневных газет и 47 еженедельников, то спустя два года в её распоряжении имелось уже 120 периодических изданий с общим тиражом 673 тыс. экземпляров [4, с. 111].

В борьбе за влияние над электоратом, германские фрашисты привлекали не только прессу. С 1930 г. гитлеровская пропаганда, считавшая слово наиболее подходящим средством воздействия на массы, начала широко использовать радио и граммофонные пластинки с речами Гитлера и Геббельса. Огромное значение имело то обстоятельство, что это слово исходило не из уст академического докладчика, а содержало магическое и эмоциональное обращение оратора, буквально гипнотизирующего толпу. Радиовещание рассматривалось как мощнейшее средство пропаганды, за которым виделось большое будущее.

В ходе избирательной кампании 1930 г. национал-социалисты впервые апробировали новую по тем временам технику - микрофоны и громкоговорители. А через два года, во время второго тура президентских выборов Гитлер при передвижении по стране использовал самолет с символичной надписью: «Фюрер над Германией». Впоследствии Геббельс констатировал, что без радио и самолетов приход НСДАП к власти были немыслимы. Он писал о радио как о «влиятельнейшем посреднике между движением и нацией, между идеей и человеком» [Цит. по: 5, с. 231].

По убеждению нацистских идеологов, пропаганда по фрорме и содержанию должна была не только соответствовать интересам самых широких слоёв населения, но и содержать минимум идей и концепций. Гитлер прямо заявлял о том, что из всего многообразия идей, составлявших нацистское «миросозерцание», он должен был «выбрать главные и центральные 
идеи и придать им более или менее законченную форму догматов, вокруг которых только и можно объединить большие массы людей» [6, с. 322]. Основную задачу своей пропаганды фюрер видел в том, «чтобы воздействовать на массу, сделать доступным её пониманию отдельные важные, хотя и немногочисленные фракты, события», о которых она «до сих пор не имела и понятия». Далее, по мнению Гитлера, требовалось «заставить массу поверить» в то, что «такой-то фракт существует, такая-то необходимость действительно неизбежна, такой-то вывод действительно правилен» [6, с. 150].

Нацистская пропаганда смогла не просто уловить, но и использовать в своих интересах особенности индивидуальной и социальной психологии немцев. В это время её характерными чертами являлись такие настроения и чувства, как неуверенность в завтрашнем дне, страх, ненависть к подлинным и мнимым врагам, уныние, а также озлобленность по отношению к новым и непривычным парламентским институтам власти, поскольку именно в них усматривался главный источник неустойчивости положения в государстве. Учитывая предрасположенность немецких обывателей к восприятию различных слухов, национал-социалисты широко использовали миф об угрозе заговора. Речь шла о «заговоре марксистов», «заговоре евреев», «заговоре плутократов», который будоражил человеконенавистнические инстинкты и способствовал росту фанатизма [3, с. 151].

Нацисты искусно спекулировали на послевоенных экономических трудностях, политической нестабильности и национальных чувствах немцев, ущемленных Версальским мирным договором. Все обещания строились на основе идей единства нации и превосходства германской расы перед другими народами. На расовой общности зиждились те неразрывные узы солидарности, которые объединяли германцев между собой. «Мы» - немцы ловко противопоставлялись национал-социалистами «им» - не немцам, иностранцам, и в особенности евреям, национальному меньшинству, «паразитирующему» на теле германцев [9].

Убежденный в том, что вся пресса находилась в руках евреев, Гитлер настойчиво и постоянно констатировал «силу так называемого общественного мнения» и «непонимание еврейской опасности», ставшей «основной решающей причиной крушения» Германии [6, c. $263,274,283]$. Фюрер самоуверенно полагал, что спасти страну от неизбежной гибели могла лишь нацистская партия. На страницах своей «Mein Kampf» он утверждал, что «только наше движение способно задержать дальнейшее падение немецкого народа, ... и создать гранитный фундамент, на котором в своё время вырастет новое государство». При этом Гитлер обещал, что это будет «подлинно народный организм» и государство, «действительно представляющее немецкую нацию» [6, с. 276].

Немецко-американская исследовательница Х. Арендт, анализируя нацистскую пропаганду, обращает внимание на тот факт, что гитлеровцы были «достаточно предусмотрительны, чтобы использовать такие лозунги, как демократия, республика, диктатура или монархия, которые обозначили бы специфические фрормы правления». Они старались их избегать и рассматривали государство лишь как средство для сохранения расы. Арендт объясняет это тем, что нацисты всегда стремились быть «исключительно оригинальными» [2, с. 471].

На основе психологических знаний нацистскими идеологами были выработаны принципы, которые легли в основу письменной пропаганды. Главным из них являлась краткость, о сущности и значимости которой Гитлер писал: «Масса косна и ленива. Люди неохотно берут в руки большие произведения, поэтому только прокламация или плакат могут рассчитывать, что они будут прочитаны ввиду их краткости» [6, с. 153]. Исходя из этого фракта, нацисты стремились преподносить свои идеи в безапелляционном стиле в фрорме лозунгов, рассчитанных на внешний эффрект. Любое сомнение или попытка самостоятельно вникнуть в суть гитлеровской идеологии рассматривались как посягательство на ее основы. Логика и научные доказательства не только не действовали, но и считались недопустимыми. Расчет делался не на разум, а на эмоции и чувства, на социально-психологические настроения в обществе. Особенно типичной для данного метода была «Mein Kampf», предлагавшая без рассуждений и дискуссий принимать на веру те или иные идеи её автора.

Примечательно, что письменная пропаганда германских фашистов использовала опыт американской коммерческой рекламы, в основе которой находилось многократное и настойчивое повторение одних и тех истин и постулатов.

Не менее значимым принципом пропагандистской деятельности нацистов была гибкость и относительно быстрая переориентация на разные категории избирателей в зависимости от политической ситуации и положения НСДАП. Так, когда в ходе первого этапа президентских выборов 1932 г. стало известно, что 
партия получила сравнительно мало голосов от государственных служащих, пенсионеров и женщин, центральный отдел пропаганды во втором туре целенаправленно сосредоточил свою работу на привлечении именно этих представителей электората. Пропагандистская кампания строилась с учётом их характера и настроений: брались во внимание страх перед будущим у государственных служащих, боязнь инфляции у пенсионеров и опасения войны у женщин [1, с. 109].

Рассуждая о практической значимости данной тактики, Гитлер советовал при разрешении невыполнимых задач сосредоточить все внимание народа на одном вопросе и «сделать это с такой силой, как если бы от этого зависела вся судьба нации» [6, с. 209]. По убеждению фюрера, человеческая психика лучше воспринимала одну идею и одного врага.

Правильность пропаганды определялась её успехом, который напрямую зависел от содержательной части первой. Чем меньше идей и теоретических постулатов содержала в себе агитация, тем действенней и успешней она являлась. Этот постулат стал теоретической основой пропагандисткой деятельности нацистов в период Веймарской республики.
Социальный и политический успех НСДАП в значительной степени был обеспечен и разговорным языком пропаганды. Для создания атмосфреры доверия и взаимопонимания с электоратом нацисты использовали простой и понятный для него стиль и язык. По меткому выражению биографра Гитлера А. Шлезингера, фюрер хорошо знал проблемы и «обиды своей аудитории, поскольку разделял их сам, и когда он говорил, то выдавал людям именно то, что они хотели» слышать [9, р. 38].

Подводя итог, можно констатировать, что рассмотренные методы и формы нацистской агитации не только учитывали морально-психологические особенности национального сознания немцев в специфических социально-экономических и политических условиях Веймарской республики, но и воплощали в себе свойства, присущие массовой пропаганде всех времен, ориентированные не на разум, а на чувства и инстинкты толпы. Всё это позволило нацистам привлечь на свою сторону самые широкие слои германского населения и, использовав технические возможности средств коммуникации и информации, завладеть их сознанием.

\section{Источники и литература}

1. Аникеев А. А., Кольга Г. И., Пуховская Н. Е. НСДАП: идеология, структура и функции. Ставрополь: СГУ, 2000. 323 с.

2. Арендт Х. Истоки тоталитаризма. М.: ЦентрКом, 1996. 672 с.

3. Бланк А. С. Из истории раннего фрашизма в Германии. Организация, идеология, методы. М.: Мысль, 1978. 208 с.

4. Бланк А. С. Старый и новый фашизм. Политико-социологический очерк. М.: Политиздат, 1982. 256 с.

5. Герцштейн Р. Э. Война, которую выиграл Гитлер. Смоленск: Русич, 1996. 608 с.

6. Гитлер А. Моя борьба. М.: ИТФ «Т-Око», 1992. 598 с.

7. Кершоу Я. Гитлер. Ростов-на-Дону: Феникс, 1997. 320 с.

8. Маклюэн Г. М. Понимание Медиа: Внешние расширения человека. М. Жуковский: «КАНОН-пресс-Ц», 2003. 464 с.

9. Рудая О. И. Антисемитизм и антиеврейская пропаганда как средство мобилизации германской нации на создание массовой базы нацистской партии в период Веймарской республики // Германия на перекрестках истории. Проблемы внутренней и внешней политики в контексте трансформаций международных отношений. Сб. научных статей. Вып. 8. Воронеж: ВГУ, 2017. С. 101- 116.

10. Schlesinger A. M. Adolf Hitler. N.-Y., 1985. 112 p.

\section{References}

1. Anikeev A. A., Kol'ga G. I., Puhovskaya N. E. NSDAP: ideologiya, struktura i funkcii (NSDAP: ideology, structure and functions). Stavropol': SSU publ., 2000. 323 p. (In Russian).

2. Arendt H. Istoki totalitarizma (The origins of totalitarianism). Moscow: CentrKom, 1996. 672 p. (In Russian).

3. Blank A. S. Iz istorii rannego fashizma v Germanii. Organizaciya, ideologiya, metody (From the history of early fascism in Germany. Organization, ideology, methods). Moscow: Mysl', 1978. 208 p. (In Russian).

4. Blank A. S. Staryj i novyj fashizm. Politiko-sociologicheskij ocherk (Old and new fascism. Political and sociological essay). Moscow: Politizdat, 1982. 256 p. (In Russian).

5. Gercshtejn R. Eh. Vojna, kotoruyu vyigral Gitler. Smolensk: Rusich, 1996. 608 p. (In Russian).

6. Gitler A. Moya bor'ba (The war that Hitler won). Moscow: ITF «T-Oko», 1992. 598 p. (In Russian).

7. Kershou Y. A. Gitler (Hitler). Rostov on Don: Feniks, 1997. 320 p. (In Russian).

8. Maklyuehn G. M. Ponimanie Media: Vneshnie rasshireniya cheloveka (Understanding Media: External expansion of a person). Moscow: ZHukovskij: «KANON-press-C», 2003. 464 p. (In Russian).

9. Rudaya O. I. Antisemitizm i antievrejskaya propaganda kak sredstvo mobilizacii germanskoj nacii na sozdanie massovoj bazy nacistskoj partii v period Vejmarskoj respubliki (Anti-Semitism and anti-Jewish propaganda as a means of mobilizing the German nation to create a mass base of the Nazi Party in the period of the Weimar Republic) // Germaniya na perekrestkah istorii. Problemy vnutrennej i vneshnej politiki v kontekste transformacij mezhdunarodnyh otnoshenij. Sb. nauchnyh statej. Voronezh: VSU publ., 2017. Issue 8. P. 101-116. (In Russian).

10. Schlesinger A. M. Adolf Hitler. N.-Y., 1985. 112 p. 